\title{
Características, referentes y líneas maestras de la crítica literaria realizada en Cuadernos del Sur
}

\author{
Features, References and Lines \\ of the Literary Criticism in Cuadernos del Sur
}

\author{
Antonio Rodríguez Jiménez \\ Universidad de Málaga
}

\begin{abstract}
RESUMEN
Este artículo aborda las características, los referentes y las líneas maestras de la crítica literaria desarrollada en el suplemento literario Cuadernos del Sur. La constancia en el terreno crítico aportó una autoridad que posteriormente generó independencia en la calidad de las obras estudiadas. Se muestra cómo la apuesta crítica fue constante y de firme compromiso con la difusión de la cultura. Se abordan discusiones y debates en torno a la crítica desarrollada entre 1986 y 2008. Se explica cómo Cuadernos del Sur ha sido una guía para iluminar a los lectores por la intrincada selva de las manifestaciones del pensamiento, sobre todo por el mundo de los libros, que ha realizado una visión crítica con libertad de planteamientos estéticos a la hora de enjuiciar la obra literaria. Se analiza cómo Cuadernos del Sur marca un camino de diálogo y se convierte en tribuna abierta de expresión de críticos y autores.
\end{abstract}

Palabras Clave: Crítica literaria; Líneas maestras y referentes literarios; Suplemento cultural; Cuadernos del Sur.

\begin{abstract}
This article approaches the features, references points and lines of literary criticism expressed in the literary supplement Cuadernos del Sur. The work constant in the literary field provided a critical authority and subsequently independence in the quality of the works studied. It shows how the gamble of criticism was continuous and strong to the dissemination of culture. It covers discussions and debates about literary criticism between 1986 and 2008. It explains how Cuadernos del Sur has been a guide to enlighten readers by the tangled jungle of the manifestations of thought, especially in the world of books, with a critical view of aesthetic approaches freely when prosecuting the literary work. It analyzes how Cuadernos del Sur it marks a path of dialogue and turns into platform of expression of critics and authors.
\end{abstract}

Key words: Literary criticism; Features and literary references; Literary supplement; $\mathrm{Cu}$ dernos del Sur. 
El suplemento Cuadernos del Sur ${ }^{1}$ marca desde sus inicios unos objetivos en el campo crítico, además de los generales en el campo meramente cultural. Se subraya, pues, que se hará hincapié en «la literatura a través de la narrativa, la poesía, el ensayo» ${ }^{2}$. También se resalta la inclusión de especialidades como la historia, la filosofía, el teatro, la música, el arte, la arquitectura, la bibliografía y otras muchas manifestaciones culturales. Pero se señala especialmente que en cada número habrá un apartado bibliográfico en el que se reseñarán las novedades y se destacarán los libros más interesantes, además de comentarios críticos y especializados para destacar los contenidos y las formas. Ya se está marcando así desde el principio que habrá un apartado selectivo, indicativo, junto a otro puramente crítico. Se habla, pues, de filtros: uno general, en donde se intentará apartar lo accesorio de lo principal, y otro esencialmente crítico, basado en libros de máximo interés para los editores de este suplemento, con todos los elementos de objetividad, y, en parte, de subjetividad, que este planteamiento pueda generar. Las intenciones están puestas sobre la mesa desde el primer número, en la nota editorial a la que aludíamos antes. Igualmente, se proyecta destacar la literatura del sur de España, y partiendo de esa base se pretende ampliar hacia lo nacional e internacional, ajustándose a factores que provengan de la calidad. El equilibrio es una constante ida y venida desde lo local a lo universal, por lo que no faltan panoramas y críticas de todas las literaturas posibles, tanto a nivel crítico como informativo. En este sentido, es fácil percibir la convivencia de temas monográficos dedicados a Calderón de la Barca junto a otros ofrecidos a Hemingway, o a la literatura catalana, china o francesa. Esa es una realidad continua que se dará en las más de dos décadas de existencia de Cuadernos del Sur.

La primera crítica que se publica en el suplemento se titula «Una antología de Carlos Clementson» y la firma P. R. (Roso, 1986), en la que hace un comen-

\footnotetext{
${ }^{1}$ Se ha analizado los mil primeros números de Cuadernos del Sur, suplemento de Cultura de Diario Córdoba, que el propio autor de este artículo, Antonio Rodríguez Jiménez, ha coordinado desde 1986 hasta 2009. El panorama estudiado comprende desde 1986 hasta 2008, lo que supone un acercamiento, en cierta medida, a la historia de la crítica literaria que abarca 22 años de existencia y más de quince mil páginas de periódico (formato tabloide). Cuadernos del Sur no es sencillamente un suplemento literario de un periódico de provincias (Diario Córdoba) sino un foco de emanación de cultura que nace en una ciudad de 300.000 habitantes y se convierte en centro de discusión y debate constante. Partiendo del estudio de un ser vivo, irradiador de múltiples conocimientos en el terreno humanístico, tales como la literatura, el arte, la música, el teatro, la arquitectura, pero sobre todo el pensamiento sobre los temas candentes, nace Cuadernos del Sur con la pretensión de informar y reflexionar sobre la cultura local. Rápidamente se contagia de todas las posibilidades culturales y se convierte en una isla desde donde se cavila y se genera discusión sobre el fenómeno creativo y crítico. En el suplemento intervienen desde escritores locales que empiezan hasta conocidos pensadores, novelistas, artistas plásticos y poetas del ámbito internacional.

${ }^{2}$ Se hace referencia, en una nota de edición sin firma, a las bases que van a regir la línea editorial de la publicación. Suplemento Cuadernos del Sur. Diario Córdoba. 1, 27-XI1986, p. 21.
} 
tario en torno al libro Las olas y los años, del citado poeta. Roso escribe que la poesía de Carlos Clementson «gira, obsesiva, reiteradamente, en torno a unos pocos registros temáticos». Añade Roso en el citado comentario que «más allá de otra consideración, se resuelve en un frondoso territorio verbal —brillante a veces, excesivo las más-, en un exacerbado amor a las palabras, en las que el poeta funda su propio mundo, al que siempre acaba por regresar» (Roso, 1986). La crítica del libro se complementa con un comentario titulado «La liturgia del verbo reconocido» donde Roso critica la falta de originalidad y el exceso de influencia de las viejas generaciones de poetas en las jóvenes, y, por consiguiente la falta de valentía para crear una voz propia y diferenciadora.

Por otra parte, el único comentario crítico sobre un libro de narrativa lo publica José Manuel Martín. Se trata de una amplia nota a la obra de Agota Kristof, El gran cuaderno, editado por Seix Barral (Martín, 1986). Martín lleva a cabo una crítica esencialmente descriptiva, en la que señala los antecedentes de esta escritora, luego explica el argumento de la obra y, posteriormente, lleva a cabo una valoración, calificándola de «ejercicio constante de contradicción», hace hincapié en antecedentes tales como dónde ha bebido la escritora, refiriéndose a Samuel Beckett, para concluir —introduciéndose en una reflexión expresada por la autora- que «el pensamiento es inútil y todo carece de sentido». Finalmente realiza una valoración global para concluir que se trata de «una novela genial», que no es una novela hermosa, sino «un cuaderno grande que tiene aún muchas páginas en blanco» (Martín, 1986). No existe, pues, una conclusión definitiva. Martín abre una puerta, orienta al lector sobre las posibilidades, se atreve a decir, incluso, que es una novela «genial», pero sus argumentos son sencillamente sugerencias, pues no se aventura a explicar concienzudamente esos puntos de genialidad de la novela. Ante estas dos líneas críticas en poesía y narrativa se abre Cuadernos del Sur al terreno de la crítica literaria.

En los primeros números, la crítica mantendrá un moderado papel y se acrecentará e instalará en sus páginas progresivamente. Los espacios dedicados a novedades bibliográficas no desaparecerán siquiera en los monográficos, como fue el caso del dedicado a Federico García Lorca ${ }^{3}$, donde se incluyen nada menos que trece libros comentados sobre el poeta.

Por su parte, José A. Cerezo Aranda comenta El cancionero moderno de obras alegres (editado en Visor en 1985). A lo largo de casi una página de texto, en el número 5, se detiene concienzudamente para analizarlo y profundiza en lo que ha sido la literatura erótica en España. Se trata, en este caso, de la edición de una reproducción facsimilar de una de las antologías festivas más características del siglo XIX. Con el comentario de este volumen,

\footnotetext{
${ }^{3}$ Se mantiene la página de novedades bibliográficas dedicada a libros de Federico García Lorca cuyas ediciones son recientes. Cuadernos del Sur. Diario de Córdoba. 4, 18-XII-1986, p. 18 .
} 
entendemos que los editores de Cuadernos del Sur lanzan un mensaje a los lectores. Se trata de la idea de que además de ocuparse de comentar las novedades editoriales, se van a dedicar espacios a la literatura histórica, que es otra manera selectiva de hacer crítica literaria. Por su parte, José Luis Amaro comenta el libro de Leopoldo María Panero Poesía 1970-1985 (Visor, 1986), donde en una columna esboza el sentido de la poesía de este escritor madrileño. En el número 6 del suplemento (Cerezo Aranda, 1987) se aborda un libro epistolar denominado Las cartas de amor de Henry Miller a Brenda Venus, obra publicada por Seix Barral en 1986 y a la que se dedica una página y abre la portada del suplemento. Cerezo Aranda destaca los elementos esenciales de este maestro neoyorquino de la narrativa erótica partiendo de las cartas que escribió a partir de los 84 años a la joven y bella Brenda Venus.

En el número 8 de Cuadernos del Sur, Pedro Roso se ocupará del volumen ¿Para qué la lírica hoy?, de Hilde Domin, (1986). El crítico hace hincapié en el sentido de la poesía a finales del siglo XX (Roso, 1987a). Analiza las reflexiones de Domin y aborda cuestiones tales como la necesidad y la autenticidad del hecho creativo, el sentido de la metáfora o la relación entre la tradición y la originalidad, situando al lector ante la génesis del texto poético para concluir en un análisis sobre la interpretación del poema fundado en la inagotabilidad del texto lírico. El volumen analizado y la manera de abordar el texto por parte del crítico marcan las intenciones de un suplemento que parte de la idea de convertirse en referente de la crítica literaria en España, una crítica de calado, que trata de abordar los textos por sí mismos, los títulos de calidad en su mayor parte frente a la propaganda editorial. No quiere esto decir que no se analicen algunas veces libros comerciales, pero la mayoría son textos de enjundia.

Una línea maestra de reflexión y profundidad la inicia Pedro Roso en su artículo «La estrategia de la diversidad», donde aborda junto al artículo anterior otro asunto de la crítica que se ha desarrollado obsesivamente. Se trata de acotar, seleccionar y fijar escalas y jerarquías. Recuerda, pues, la costumbre - muy académica- del cuestionado concepto de generación. Subraya cómo después de las generaciones del 98 y 27 todo se ha organizado con esa palabra, y sirvan de ejemplo las generaciones del 50, 60, 70, 80 y 90, aunque ya en los últimos años se le denominaría diversidad, lo que sería una manera elegante de disfrazar el contexto para decir que se ha desarrollado una pluralidad de propuestas estéticas. Pero si se analiza detenidamente será fácil observar que lejos de dicha pluralidad ha habido dos grandes grupos: una poesía que se ha desenvuelto en una línea «clara», heredera de la poesía social, frente a una línea de poesía culta, de corte más clásico y hermético. Una y otra han sido veladas por los críticos con diversas nominaciones y a esto es a lo que superficialmente se le ha llamado pluralidad.

En el campo de la narrativa ha habido cierta preocupación estilística, pero pocas aportaciones reales. La originalidad ha pasado a un segundo plano y de 
un masivo interés por el realismo se ha pasado a una diversidad expresiva donde el camino de la genialidad no aparece por ninguna parte. Roso se pregunta: ¿La diversidad es sinónimo de riqueza? ¿O estamos ante una estéril redundancia? El final de su reflexión es duro pero abre las puertas de la meditación y búsqueda de un camino crítico en el que Cuadernos del Sur va a profundizar durante más de dos décadas: «Sustraerse a éstas y otras consideraciones no revela sino la actitud de una crítica que, instalada cómodamente en el escepticismo o la complacencia, ha hecho dejación de sus funciones. ¿O es que la crítica tampoco tiene que cumplir función alguna?» (Roso, 1987b). Este crítico no estuvo mucho tiempo en el suplemento pero fue uno de los que abrieron el camino que luego seguirían otros de los que iremos comentando más adelante.

\section{LA POESÍA EN LOS PRIMEROS IMPULSOS CRÍTICOS}

En los números 9 y 10 de Cuadernos la incidencia sobre autores cordobeses se agudiza con comentarios y dedicación de espacios a Álvarez Ortega, Juana Castro, Leopoldo de Luis, José de Miguel, José Luis Amaro, Rafael Álvarez Merlo o Francisco Gálvez. Se trata de un elemento muy significativo a la hora de marcar las líneas maestras de la crítica de una publicación que llevaba en marcha en ese momento apenas tres meses y debe poner de manifiesto la existencia de sus autores, de poetas en ese caso, que es lo que más abundaban, para partir de lo local y entrar en correspondencia con lo nacional e internacional. En este sentido, Pedro Roso reivindicará el valor y la fuerza de los poetas Amaro, Álvarez Merlo y Gálvez, trío que forma por entonces la denominada revista Antorcha de Paja, que jugó, por cierto, un papel importante en la poesía local y andaluza de los años setenta. En ese número del suplemento, Roso pretendía reivindicar la aportación del grupo cordobés, que mostraba sus preferencias por el poema breve frente al derroche verbal en el que incurría buena parte de la poesía de aquellos años. Y frente a cierto irracionalismo imperante, aquellos tres cordobeses reclamaban un racionalismo fundado en la introspección como búsqueda interior. Ellos postulaban que la vida fuera teoría poética del hombre y la poesía, afirmación de la existencia. No obstante sus poéticas, a partir de aquellos planteamientos comunes, discurrieron por caminos y estilos diferentes entre sí (Roso, 1987b).

El número 21 abre con un homenaje a la generación poética del 50, de la mano también de Roso ${ }^{4}$, que comenta tres libros aparecidos por esas fechas sobre la citada generación ${ }^{5}$. Destaca, por un lado, la visión de Debicki par-

\footnotetext{
${ }^{4}$ Es interesante la visión de Pedro Roso (1987d) sobre la generación del 50.

${ }^{5}$ Los libros reseñados son los siguientes: José Luis García Martín (1986 y 1987) y Andrew P. Debicki (1987).
} 
tiendo de dos conceptos básicos: la autorreferencialidad y la intertextualidad. Escribe que la visión de García Martín se presenta como un planteamiento histórico-crítico, que bucea en sus orígenes y describe su desarrollo. Ambos coinciden en que el grupo del cincuenta se ha convertido en el dominante de posguerra desde mediados de los años setenta. Señala Roso, poniendo de relieve el análisis de Debicki, que la originalidad de los temas que tratan estos poetas no reside en la novedad del lenguaje que emplean sino en la forma precisa y creativa de tratarlos. García Martín subraya que se trata de una generación cumulativa. Ambos señalan que lo importante es su concepción poética, la devolución al lenguaje poético de parte de la importancia que había tenido para la generación del 27. El tiempo, el misterio de la existencia y las relaciones con los hechos concretos de la vida constituyen la tópica generacional. Evocaciones de la infancia y juventud, amor y otros detalles forman parte de esa poesía del medio siglo. Poetas como Claudio Rodríguez, Ángel González, Francisco Brines, Jaime Gil de Biedma o José Ángel Valente serán algunos de los poetas objeto de estudio.

Vázquez Montalbán también es abordado a raíz de la aparición de sus libros Pigmalión y otros relatos (Seix Barral, 1987) e Historias de padres e hijos (Planeta, 1987). Pedro Roso hace una especie de semblanza con carácter didáctico para presentar al personaje. Comenta los libros y habla de su pensamiento, de sus crónicas periodísticas, de su narrativa y de su poesía. También describe al personaje, a Carvalho, denominándolo «escéptico espectador» que le permite describir la realidad de una sociedad plagada de contradicciones y sospechas. En definitiva, el crítico sirve aquí de enlace entre el lector y el autor e invita indudablemente a su lectura. En este caso, más que llevar a cabo una crítica al uso - la hace indudablemente-, invita a los lectores a leer la obra de Manuel Vázquez Montalbán (Roso, 1987c). Se completa este comentario con una entrevista a cargo de Gonzalo Pérez Ponferrada, donde el conocido escritor barcelonés manifiesta que «escribir ha sido mi única posibilidad de comunicación» (Pérez, 1987).

El crítico José Luna Borge publica un comentario muy áspero -aunque bien documentado y contrastado- sobre el libro Los vanos mundos, del escritor gaditano Felipe Benítez Reyes (Diputación de Granada, 1985), donde califica el poemario de «discreto libro de poesía con una mitad de poemas de aprendizaje, espléndidos ejercicios de taller, de alumno aventajado» (Luna Borge, 1987a). Críticas de estas características, francas y abiertas, tendrían en este suplemento - después de los primeros números - un amplio campo de cultivo, convirtiéndose en otra línea maestra del mismo. Poesía, narrativa y ensayo irán abriéndose hasta crear auténticas canchas dialécticas en el terreno crítico y no solo desde un punto de vista formal, sino también puramente sociológico e ideológico.

Críticos y profesores como Sanz Villanueva y Fanny Rubio, colaboradores esporádicos del suplemento, dejan un impecable sello de calidad en las 
páginas del mismo. En esta línea maestra de la crítica habrá docenas de firmas invitadas, ocasionales, que servirán para fortalecer el terreno crítico de Cuadernos. En este sentido, ambos abordaron al escritor Manuel Andújar, poeta republicano y andaluz en el exilio, nombrado Hijo Predilecto de Andalucía y homenajeado a finales de los años ochenta. Cuadernos del Sur se sumó a dichos homenajes con sendos artículos de Sanz Villanueva (narrativa) y Fanny Rubio (poesía), con los que se producía un acercamiento crítico a su trayectoria humana y literaria (Sanz, 1987 y Rubio, 1987). En ese mismo número comienza a colaborar el crítico asturiano José Luis García Martín con un comentario titulado «El humor, la poesía», sobre el libro de Jon Juaristi (editado en Pamiela, 1987) Suma de varia intención.

En el número 30 de Cuadernos del Sur, José Luna Borge se adentra en la obra poética de Javier Salvago para destacar que se trata de una de las voces más interesantes de la joven poesía del momento. Señala la abundancia de recursos expresivos y semánticos, además de los rítmicos y los métricos, haciendo hincapié en el lenguaje coloquial, al que se recurre para darle viveza al asunto. Utiliza la ironía y subraya que con vocablos poco poéticos se puede conseguir buena poesía. También emplea un tono confesional e íntimo. El crítico insiste, igualmente, en el análisis de la forma para demostrar que el resultado del poema es el manejo del equilibrio entre el fondo y la forma. Advierte, no obstante, que el excesivo coloquialismo puede generar en verborrea, así como el abuso del tono confidencial del que pecan los poetas de la estética neorrealista. Salvago estaría - según Luna Borge- en esa línea de auténtica poesía que surge de la propia experiencia del creador y que proviene de una tradición «hoy casi olvidada», de Corbière, Laforgue, Eliot, Manuel Machado, Moreno Villa, el Cancionero popular andaluz, Gil de Biedma y otros. Escribe que se «configura en solitario como una de las más sugerentes vetas o tendencias de la poesía joven actual» (Luna Borge, 1987b).

Después de un año de andadura de Cuadernos del Sur comienza otra etapa crítica con la participación activa de firmas como José Luis García Martín en poesía, Pedro Domene, José A. Cerezo Aranda, Pedro Ruiz, Manuel Ariza Canales y Antonio Enrique en narrativa o José Manuel Cuenca Toribio en historia. También comienzan a escribir críticas regularmente Juana Castro y Carlos Clementson. Como críticos ocasionales lo hacen Juan Bonilla, Manuel Peñalver, Juan Lamillar, Antonio Cruz Casado, María José Porro, Miguel Ángel Toledano, Javier Sánchez Menéndez, José Luque, Ángel Aroca Lara, Carlos González Espina, Juan Ruiz y Juan Pérez Cubillo, entre otros. Precisamente en el número 34 el escritor y poeta Jacinto López Gorgé hace una reflexión titulada «Profesionalidad de la crítica», en la que sostiene que páginas propiamente literarias las mantienen los periódicos nacionales de diarios como ABC, El País, Ya, La Vanguardia y Diario 16. López Gorgé manifiesta en su artículo que la situación de los críticos en los periódicos no es muy halagüeña, debido a que no se valora suficientemente el trabajo de crítico literario (López Gorgé, 1987). 
También se incorpora el profesor de Filosofía Ramón Román Alcalá con un comentario sobre el volumen La secta del perro, donde García Gual profundiza en Diógenes Laercio y en aquel movimiento griego negador de todos los valores. A partir de ahí permanecerá en el suplemento siempre. También se incorporan por esas fechas cuatro críticos nuevos, tres de narrativa, Ángel Estévez Molinero, que se convertirá en uno de los más asiduos durante algunos años, así como Luis Alonso Girgado (que se encargará durante mucho tiempo de la narrativa hispanoamericana), Bernardo Ríos (para todo lo referente a la ciencia ficción y al cómic) y otro de teatro y ensayo literario, Luis Sánchez Corral. Este grupo de analistas literarios marcarán otra línea maestra crítica consistente en la acentuación del rigor, el didactismo y el aumento paulatino de la transparencia expresiva, además de la actualidad a la hora de seleccionar los temas objeto de estudio en los diferentes géneros.

José Luis García Martín se ocupa de un libro de Pere Gimferrer titulado Poemas 1962-1969 (Visor, 1988), donde hace una defensa a ultranza de la obra del poeta y critica la edición realizada para confeccionar este libro (García Martín, 1988a). Igualmente se ocupa del volumen Curso superior de ignorancia (Universidad de Murcia, 1987), de Miguel D’Dors, del que escribe que es fruto de «una refinadísima e inteligente manipulación del material verbal». También explica que D'Ors pertenece a ese grupo de poetas que viven al margen del «tinglado» de la sociedad de consumo literario (García Martín, 1988b).

El crítico Francisco López Gutiérrez plantea la angustiosa realidad de seleccionar a la hora de elegir un libro entre miles de novedades. Hace el planteamiento a partir de la aparición en el mercado editorial de dos libros de Ignacio Vidal Folch: No se lo digas a nadie (Anagrama, 1987) y El arte no paga (Anagrama, 1988). El crítico se queja de la desmesura de la oferta de mercado de la narrativa, la pluralidad de los fenómenos y del vértigo en la sucesión de los acontecimientos que justifican los reparos del estudioso «a enfrentarse con este erial de papel impreso no clasificado e inclasificable». Reflexiona y se pone en el lugar de un lector que se acerca a una librería con la intención de adquirir «algo para leer». Explica que si exceptuamos a los clásicos y al corto número de famosos superpublicitados por los medios de comunicación, el panorama que se le ofrece resulta tan abigarrado y equívoco como peligrosa la elección. Subraya López Gutiérrez que las estrategias elegidas por las editoriales giran en torno al apoyo a ciertas tendencias creativas conectadas con modas artísticas y sociales de repercusión mundial - los estrictos valores literarios del libro quedan, por tanto, en segundo términoy la clasificación de las obras mediante su inserción de colecciones bastante homogéneas, que orientan al consumidor - a la manera de los luminosos de los Vips, Burgers o McDonalds- sobre las características del objeto a consumir, más cualificado por la imagen de marca que por su identidad individualizadora (López Gutiérrez, 1988). 
Tras un preámbulo explicativo de la situación actual, donde el crítico ha de estar ojo avizor para que el editor no le «disfrace» de calidad un producto comercial de segunda fila, que es lo que suele ocurrir en los grandes periódicos debido a los intereses comerciales de grupo, se refiere a lo urbano como corriente de moda en la poesía y muy especialmente en la narrativa. Recuerda que existen colecciones de narrativa urbana. En este caso cita una de las de más prestigio a pesar de indicar una tendencia, como es la colección Contraseñas de Anagrama, donde han tenido cabida Bukowski, Copi, Sharpe, Douglas Adams, Quim Monzó, Raúl Núñez o Andréu Martín, entre otros, además de Jesús Baray, Sergi Pámies o Vidal Folch, éstos últimos de generaciones más jóvenes. A partir de una larga introducción reflexiva sobre el panorama actual, Francisco López Gutiérrez entra en las obras de Folch. Realiza un análisis pausado y viene a concluir que estas obras están inscritas en lo que se denomina literatura de entretenimiento, siempre fácil y atenta a los requisitos básicos del género, por lo que considera que presenta la misma problemática que tantos otros productos de la joven narrativa urbana y que el usuario la consume sin más algarabías, pero situándose de continuo en el peligroso límite del aburrimiento de lo archiconocido, de llegar al convencimiento de que a uno lo están vistiendo una y otra vez con el mismo traje. Termina manifestando que cuando eso ocurra no quedará otra salida que «la de cerrar la tienda e inventar otra narrativa, claro está» (López Gutiérrez, 1988). Esta línea crítica abierta, sin intereses culturales, es muy valorada por los amantes de la literatura y se va afianzando a lo largo de la existencia de Cuadernos del Sur.

\section{TEORÍA CRÍTICA EN EL PANORAMA NACIONAL}

Sobre la crítica que se hace en España en esos momentos, Carmen Martín Gaite manifiesta en una entrevista, que se suele hacer una crítica ocasional, no muy rigurosa, pero reconoce que dentro de esa crítica un poco más al salto de los libros que van saliendo: «a mí la crítica que más me gusta y la que yo procuraré hacer cuando me dedique a ello es la de no casarse con nadie, es decir, un comentario de lectura, un comentario del texto, sin andar pensando en la obra anterior que tiene ese autor, ni si en este momento está muy puesto en la ola». Añade que en España — y ella supone que en otros países— «se dan mucho los cotarros, cosas ajenas a ese texto, un respeto intocable, por ejemplo, a algo o a alguien que no se puede discutir o circunstancias como que ese libro pueda estar de moda. Es decir, un terreno donde cabe lo espurio, donde caben unos cotarros marcados por expectativas de mercado, por la publicación a la que se dirija, y de eso no estamos libres, pero a mí la crítica que más me gusta es aquella en la que, después de leerla, te has enterado de si a ese señor le ha gustado el libro o no, de verdad. Y se hace poca de ésa» (Sueiro, 1988). La 
opinión de Carmen Martín Gaite en esta entrevista realizada por Susana Sueiro es muy interesante y viene a subrayar cómo en los primeros cien números de Cuadernos del Sur se afianza la calidad crítica desde la propia intención de hacerlo hasta los resultados obtenidos, que no son pocos.

Otra línea maestra consiste en que en numerosos momentos de la trayectoria de Cuadernos se hace normal que determinados suplementos sean dedicados, íntegramente o en su mayor parte, al comentario de libros. El número 93 se abre con una crítica del libro La hija de King Kong, de Fernando Arrabal y sigue con otros volúmenes de autores como Sergio Pitol, Pedro García Montalvo, Rafael Pérez Estrada, Pietro Civitareale, August Derleth y Pessoa, entre otros.

La madurez de Cuadernos del Sur alcanza su primera época de esplendor a los dos años y medio de su puesta en marcha. En este sentido, se publica un artículo de Pedro Roso titulado «Límites y función de la crítica literaria». Como subrayamos anteriormente, el papel de Roso como crítico en la primera etapa de este suplemento va a ser crucial, pues ayudará a marcar el camino de un tipo de crítica clara y selectiva en lo referente a la calidad literaria. A principio de 1989 el panorama es el siguiente: nos hallamos ante el hecho de que la crítica literaria no goza de buena imagen, sobre todo entre los autores. Especialmente es porque los críticos se ven obligados a explicar su labor e incluso a justificar su existencia. Roso dice que se les acusa de la gratuidad de sus opiniones y de subjetivismo en sus métodos. Parece ser que editores y lectores temen a la crítica. Prueba de ello es que en las solapas y contraportadas de los libros se reproducen frases de los críticos sobre obras anteriores de los autores. Subraya que en una encuesta realizada por la revista El Urogallo, publicada en mayo de 1987, se decía que el 34 por ciento de los lectores habituales admitían que en la selección de sus lecturas influían preferentemente las críticas publicadas. Hoy sería muy difícil aseverar eso, ya que la influencia del crítico ha disminuido notablemente en los últimos veinticinco años, hasta el punto de que la televisión o el boca a boca tienen una influencia sobre la selección de libros mucho más importante que la de los críticos. No obstante, influye notablemente una reseña o una entrevista en los medios de comunicación (e incluso una crítica) que el hecho de que no aparezca nada (Roso, 1989).

Otra visión crítica, que sigue la línea maestra más reflexiva y exigente, es la reflexionada por el profesor Antonio Chicharro Chamorro en un artículo titulado «Sobre el conocimiento crítico literario». Pone sobre la mesa la idea de si existe una crítica literaria universitaria y otra periodística. Explica que la crítica literaria es un discurso interpretativo y valorativo, no científico, esto es, independizado de la teoría y fascinado por su objeto. Dice que así entendida posee unos claros objetivos: consumo literario del texto e interpretación o valoración literaria del mismo conforme a determinadas concepciones esenciales de la literatura. Subraya que teoría literaria y crítica literaria no se in- 
terrelacionan, pues están situadas en distinto lugar. Sostiene que la crítica cultivada en los periódicos habitualmente no puede ser juzgada con respecto al conocimiento teórico literario en términos de calidad. No se trata de un conocimiento peor ni mejor, sino otro conocimiento literario, pues, diferente es su proceso de producción como su función social. A la crítica periodística la llama ideológica y a la otra, científica, que se distinguen por sus funciones sociales (Chicharro, 1989).

José Luis García Martín escribe que es clave la figura del responsable del suplemento, un coordinador que se responsabilice del producto y que posea una sensibilidad para las cuestiones culturales, de modo que acierte a dotar de personalidad a la publicación y que evite que se convierta en amorfo boletín de novedades. Sostiene que el director del suplemento no debe perder de vista nunca el público al que se dirige, bastante más heterogéneo que el de una revista especializada. Un director en exceso genialoide puede producir el efecto contrario, es decir, alejar al común de los lectores en lugar de acercarlos a la literatura. García Martín critica al antiguo coordinador de Culturas (suplemento de Diario 16), José Miguel Ullán, del que dice que no hacía concesiones a la actualidad informativa y sus suplementos resultaban «ilegibles incluso para el más paciente de sus lectores» (García Martín, 1989). Para el crítico, la información bibliográfica y la reseña de las novedades más destacadas deben ser la columna vertebral del suplemento.

Otro tema es la polémica sobre quién debe realizar las reseñas, si críticos fijos o colaboradores esporádicos. Posiblemente lo más apropiado es que haya un equipo consolidado y que participen también otros especialistas. García Martín recuerda en su artículo, a modo de ejemplo, que en Sábado Cultural — suplemento de $A B C$ - se inclinaron por la primera opción, la de los fijos, con críticos como Florencio Martínez Ruiz, Miguel García Posada o José García Nieto. En El País/Libros se prefiere que el propio autor sugiera el nombre del reseñista. Explica los inconvenientes del primer sistema en el que dice a modo de ejemplo que si a Miguel García Posada le entusiasma el conceptualismo minimalista, el $A B C$ elogiará antes al más ínfimo discípulo canario de Andrés Sánchez Robayna que a cualquier poeta importante que siga otra tendencia. Y las inconveniencias del segundo sistema son los panegíricos y loas correspondientes. Sobre las características de un buen crítico sostiene que debe poseer una información adecuada, criterios firmes para no confundir con los caprichos arraigados, e imparcialidad.

Por su parte, Antonio Garrido Moraga argumenta que la obra literaria es un Jano que necesita creación y crítica. Añade que la crítica es también creación y no una actividad parasitaria, que en los periódicos se convierte en una labor de ordenación y de clasificación. Se trata, pues, de un trabajo efímero y debe ser clara en el estilo, precisa en los contenidos y sugeridora de sentidos. Analizar y valorar son los dos polos esenciales de la crítica. El crítico debe establecer relaciones entre la obra y el receptor para desvelar algo y crear 
inquietud. El crítico ideal debe ser imparcial y honesto, aunque en su trabajo esté presente la subjetividad, pues ha de tener conciencia de sus limitaciones y exigirse un trabajo de exploración previo para establecer una primera selección en el material de que dispone. Para Garrido la crítica en los periódicos es necesaria y posee una validez axiomática. Dice que contra la acusación de que la crítica de los periódicos es «superficial y divulgadora, hay que demostrar lo falso del aserto». Efectivamente, hay libros de crítica muy superficiales, artículos científicos que no pasan de ser un pretencioso ejercicio escolar, pues la profundidad de la crítica no está ni en el lugar ni en la extensión del artículo (Garrido, 1989).

La crítica en los periódicos, con su carácter divulgativo, de dar a conocer, de aclarar, de sensibilizar, ofrece tareas nobles que no tienen por qué abdicar de un riguroso planteamiento y desarrollo. Obviamente, el crítico de prensa tiene que cuidar la obra sobre la que escribe, pues una mejor crítica necesariamente conduce a una mejor literatura.

Por su parte, Pedro Ruiz Pérez aborda enteramente el carácter académico de la crítica. El profesor manifiesta que la crítica periodística discurre contratando con sus modelos las realizaciones artísticas, pero sin dejarse contaminar por ellas, porque proyecta en ellas la misma imagen de actividad desinteresada que pretende reclamar para su propia justificación. Escribe que el crítico - y se refiere especialmente tanto al académico como al que pretende serlo- no incorpora a su discurso la conciencia de sus limitaciones, de sus propias servidumbres. Subraya que la crítica se disfraza muchas veces con el ropaje más o menos pretencioso de cientificidad para usurpar el protagonismo del discurso literario, de modo que la crítica es más leída que la creación, los datos de las solapas del libro son más frecuentados que su propio contenido, y éste leído con los ojos de la crítica que impone los juicios axiológicos del gusto como objetivos al silenciar el relativismo inherente de los mismos.

Ruiz Pérez subraya que el crítico es un escritor, el emisor de un discurso, y, como tal, debe asumir en él, en su propio lenguaje, sus personales deficiencias, su irrenunciable identidad y su innegable condicionamiento ideológico. Sólo a partir de este posicionamiento, de esta declaración de principios, que implica la confesión de su papel de eslabón en la cadena de mercado, el crítico puede acercarse a su función más creativa y liberadora, aquella por la que gacetillas y suplementos dejan de actuar como formas de publicidad encubiertas y se acercan a un papel menos distorsionante en los procesos de comunicación artística (Ruiz Pérez, 1989).

\section{CONSTANTE REFLEXIÓN SOBRE LA CRÍTICA}

La constante reflexión sobre la crítica y su papel en los periódicos estuvo siempre presente en Cuadernos del Sur y fue, por tanto, una de sus líneas 
maestras. Fue tal la importancia que se le estaba dando a su papel que la Asociación Española de Críticos Literarios decidió celebrar en Córdoba la edición de 1990. El suplemento le dedicó un monográfico de 16 páginas ${ }^{6}$ donde escribieron desde Dámaso Santos hasta Rafael Conte, además de Miguel García Posada, Basilio Losada, Alex Broch, Jon Kortázar y Juan Malpartida, entre otros, todos ellos miembros del jurado de ese año. El jurado lo formaron, además de los antes citados, Ana María Navales, Enrique Baena, Carlos Galán, Santos Alonso, Fernando Valls, Ángel Basanta, Constantino Bértolo, José Antonio Ugalde, Fernando Ortiz, Luis Alberto de Cuenca y el autor de este artículo, en sus modalidades de poesía y narrativa en castellano, gallego, euskera y catalán. Dámaso Santos se encargó de escribir en Cuadernos del Sur la historia del premio desde que se instituyó a mediados de los años cincuenta hasta el 7 de abril de 1990, que era la fecha exacta en que se celebraron los fallos del premio de ese año. Además de una serie de artículos en los que se analizaba el papel de la crítica, se preparó una especie de encuesta en la que participaron 27 destacados escritores (también críticos y editores) para opinar sobre la importancia y calidad de la crítica en España y esencialmente la que se escribía en los periódicos.

Participaron en dicha encuesta personalidades de las letras como José Luis Cano, Pablo García Baena, José Agustín Goytisolo, Vicente Núñez, Antonio Gamoneda, José Manuel Caballero Bonald, Antonio Muñoz Molina, Antonio Enrique, Luis Antonio de Villena, Ángel Estévez, José Luis García Martín, Juan Barja, Javier Lentini, Antonio L. Bouza, José Lupiáñez, Luis Jiménez Martos, Julio Quesada, Jorge Herralde, José Manuel Lara, Vicente Molina Foix, Juan Campos Reina, Luis Alberto de Cuenca, Santos Sanz Villanueva y Antonio Hernández, entre otros. La participación de estas personalidades del mundo literario demuestra la consolidación de Cuadernos del Sur a los tres años de su aparición.

En esas páginas del suplemento manifestaba Antonio Gamoneda sobre las dificultades de elegir el mejor título del año, que los libros que han leído unos probablemente no los hayan leídos otros, lo que dificulta enormemente el proceso. «Los críticos no tienen la culpa», manifestaba el poeta. También subrayaba que el incremento de ventas tras el galardón no será demasiado significativo. Por su parte, Luis Alberto de Cuenca explicaba que el gusto de los lectores no coincide en ocasiones con el de los críticos que fallan el Premio de la Crítica, pues «estamos acostumbrados a ver libros importantísimos arrumbados en los estantes de las librerías, sin que una mano amiga los ojee, no hojee, ausentes de las páginas de suplementos culturales y de revistas literarias, y existen libros escasamente interesantes, que pueblan las portadas de

${ }^{6}$ La mayoría de los miembros del jurado decidieron aportar sus opiniones en el suplemento que apareció el mismo día de la reunión. Cuadernos del Sur. Diario de Córdoba. 155, 5-IV-1990. 
las revistas y se venden mejor que bien. Todo en el mundo ocurre de una forma azarosa y arbitraria» ${ }^{7}$.

Por su parte, Caballero Bonald manifestaba que no creía que el Premio de la Crítica ejerciera ningún influjo en el gusto o sensibilidad de los lectores. Dámaso Santos defendía el premio, sin dotación alguna, porque significa estrictamente el juicio anualmente emitido por la crítica ejerciente en él representada sobre los libros de poesía y novela publicados. También preservaba el valor de la propia reunión en sí como reflexión y discusión entre los militantes de la crítica sobre la actualidad literaria de España cuyo latido histórico perciben cada día y en esta ocasión subrayan.

Sobre la crítica de poesía escribía Miguel García Posada, en un artículo publicado en ese mismo monográfico, que se encuentra hoy en España en el mismo lugar que la creación poética: en las catacumbas. «Basta ver los suplementos literarios para darse cuenta de que las reseñas poéticas ocupan, cuando los ocupan, lugares visiblemente secundarios. Mandan el mercado, mandan las listas de libros más vendidos —y quizás no leídos-, y en este marco la poesía poco tiene que hacer». García Posada califica la situación de penuria y subraya que si la creación poética interesa poco, su crítica interesa menos aún y los críticos huyen, en general, de reseñar libros de versos. Las reseñas, pues, «se refugian en los dominios de los poetas, y aquí el amiguismo y el clientelismo — viejas plantas nacionales - hacen su agosto» (García Posada, 1990). Para el crítico no hay alternativas a la situación mientras la poesía padezca la indiferencia social que hoy padece. Señala con insistencia que las reseñas ceden, con demasiada frecuencia, el paso a las concordancias amicales o a los efluvios de lo inefable.

Rafael Conte hace un análisis de la situación ante la crítica de novela. Se refiere al alud narrativo ocurrido a principios de los 80 , tras la aparición de escritores como Julio Llamazares, Juan José Millás, Rosa Montero, Jesús Ferrero, García Sánchez o Muñoz Molina, donde se percibe — escribe- dispersión, desorden y sensación de caos porque «cada cual escribía como quería, sin seguir senderos impuestos, buscando su propia verdad estética y narrativa». Califica a Mendoza de irónico, a Llamazares, de tradicional, a Pombo, de filosófico, a Millás, de existencial, a Merino, de mítico, a Montero, de realista, a García Sánchez, de trágico, y a Puértolas, de clásica. También se refiere al humor de Tomeo o a la nostalgia elegante de Sánchez Ostiz. Tras hacer un amplio panorama de los narradores de esos años, explica Conte que da la impresión de que público y crítica están profundamente divorciados. «Esto no es grave, pues siempre lo han estado, aunque lo necesario es entonces abrir debates y canales de comunicación, y es deber de la crítica analizar

\footnotetext{
${ }^{7}$ Estas declaraciones forman parte de una encuesta titulada «Cuatro cuestiones sobre un premio», publicada en la página 28 de Cuadernos del Sur. Diario de Córdoba. 155, 5-IV1990, pp. 27-31.
} 
constantemente este divorcio. Otras veces, parece como si no se criticasen obras, sino otras críticas, y que la obra literaria no sea sino un pretexto para estériles batallas periodísticas. Todo ello es lamentable, pues contribuye al nerviosismo ambiental. En realidad, debiéramos olvidarlo todo y volver a leer como es debido, pues en el libro está la verdadera salvación» (Conte, 1990).

Juan Malpartida se ocupa de un género difícil para la crítica, como es el ensayo, considerado menos importante que la narrativa, pero más asiduo cada día en las páginas literarias de los periódicos. Sostiene Malpartida que el ensayo está lejos de parecer autosuficiente y su gracia tal vez le venga de la postura interdisciplinar, de su parecido con la conversación inteligente y apasionada. También manifiesta que el ensayo tiene algo de actitud moral y espiritual. Malpartida asegura que el ensayo en España ha sido más bien escaso e inexistente en algunos periodos de nuestra historia (Malpartida, 1990).

En un artículo titulado «El lector como crítico y el crítico como lector», Juan José Lanz (1991) plantea que la lectura crítica debería establecerse como un grado distinto, más profundo de lectura o dicho de otra forma, el crítico debería ser un buen lector de una determinada obra literaria o de varias, un lector capaz de presentar, sustentar de modo más o menos coherente aquellas intuiciones que el lector habitual tal vez perciba pero no sepa exponer. La labor, pues, del crítico literario podría seguir dos caminos distintos: bien llevar hasta sus últimas consecuencias una intuición lectora y sustentarla de la forma más coherente posible o aproximarse al lector potencial que pudiera realizar todas las lecturas posibles de una obra literaria. Sostiene que ambas posibilidades son utópicas y por lo tanto el crítico literario solo podrá avanzar en estos dos caminos señalados pero sin alcanzar su fin.

La crítica literaria se ha establecido como una visión distanciada de la obra literaria y como una ruptura frente a ella para interpretarla y diseccionarla. El crítico, pues, aparecerá no como parte del proceso sino como elemento independiente del mismo. Lanz manifiesta que la lectura que realiza el crítico es una especie de lectura irónica de la obra literaria en cuanto que nace distanciada de ella y discurre en un plano paralelo al de la creación literaria -él la llama plano de la creación científica-. La consecuencia última de este tipo de crítica es la construcción de entelequias autónomas. Concluye que de lo que realmente está necesitada la creación artístico-literaria es de aquella que realizan los buenos lectores. Defiende, pues, una crítica inteligente, objetiva, no manipulada, sin intereses empresariales ni estéticos y esa crítica solo la pueden ejercitar los buenos lectores que se acercan a la obra sin complejos de ningún tipo (Lanz, 1991).

Por su parte, José Luna Borge sostiene en una amplia reflexión titulada «Crisis crítica», que creadores y críticos están condenados a no entenderse jamás, culpando a la anarquía literaria y crítica predominante. También culpa a la reseña rápida, a los resúmenes de encargo y al comentario elogioso realizado por compromiso de amistad que engaña y desorienta al lector y, sobre 
todo, a la formación de grupos cerrados, que él denomina «capillitas», tanto a nivel crítico como editorial. Partiendo de esas premisas algo pesimistas, Luna Borge realiza un recorrido histórico por los caminos críticos para aclarar que eso ha ocurrido siempre, pues - escribe- en los grupos cerrados siempre ha habido un «pope» que pontificaba y esto ha hecho mucho daño a la literatura. Ve como negativo el que de la proliferación de revistas y suplementos culturales en la prensa hayan surgido muchos críticos que se piensan maestros consumados en el oficio, «a pesar de no ser más que gacetilleros que hablan de libros que no han leído» (Luna Borge, 1991: 28). Esta idea de Luna Borge se detecta no solo en revistas y periódicos poco importantes sino en los de tirada nacional. Es fácil, en ciertas ocasiones, observar que la mayor parte de un comentario crítico gira en torno a la publicidad sobre el libro enviada por la editorial y el porcentaje restante a comentarios superficiales sobre el libro propiamente dicho, lo que hace llegar a la conclusión de que no se trata de un problema del medio sino del crítico que acomete el comentario, de sus prisas y de sus compromisos con la editorial de turno.

Continúa Luna Borge escribiendo que «existen verdaderos especialistas en el tema que mirando las solapas, la leyenda trasera de la cubierta y el apunte biográfico del autor confeccionan tres o cuatro críticas diarias. Todo ello ha creado un ambiente de desorientación y anarquía literaria donde el mayor perjudicado es el público que no encuentra una autoridad en quien depositar su confianza a la hora de dirigir y encauzar su gusto» (Luna Borge, 1991: 29). El autor de este artículo arremete abiertamente contra la profesionalidad de los críticos. Y, efectivamente, puede haber críticos fútiles o gacetilleros como en diversas profesiones hay profesionales que rayan en una imperfección manifiesta, pero igualmente hay eminencias en todos los ámbitos independientemente del lugar donde trabajen. Explica José Luna que la falta de estatus del crítico le impide realizar una tarea reflexiva y realizada a largo plazo. Puntualiza de nuevo que la crítica que se exhibe en revistas y periódicos — salvo excepciones - se ha visto reducida a pura gacetilla, pues los estudios largos y rigurosos ocupan mucho espacio, no venden y, en consecuencia, son sistemáticamente rechazados.

La falta de espacio puede convertirse en una excusa para arremeter contra la labor de un crítico. Una buena crítica — un libro bien leído, documentado, expuesto y valorado- puede desarrollarse perfectamente en un folio, en cinco, en veinte o convertirla en un ensayo. El espacio del que se dispone no puede ser nunca una excusa. Lo importante es la honestidad del crítico y el desarrollo de su trabajo, que se puede realizar en un humilde periódico de pueblo, en un suplemento nacional o en una revista de estudios críticos de una universidad prestigiosa. Lo importante, pues, no es el continente sino el contenido. Efectivamente, muchas publicaciones desarrollan prisas desbocadas por presiones editoriales o por presencia manifiesta de publicidad sufragada en sus páginas, y aparecen críticas incluso antes de que los libros hayan llegado a 
las librerías. Las editoriales dan a los críticos todo tipo de facilidades, pero ya no estamos hablando de crítica literaria sino de publicidad encubierta, que se puede practicar en cualquier medio de comunicación.

Ese tipo de presiones son difíciles de visualizar en un medio de comunicación como Cuadernos del Sur, al menos en sus primeros diez años, ya que la empresa gozaba de una independencia notable en lo que a grupos editoriales se refiere y no llevaba publicidad de editoriales en sus páginas. Posteriormente, entra a formar parte del Grupo Z, y la presión de Ediciones B y otras editoriales del grupo comienza a manifestarse, aunque en ese caso las «prisas editoriales» se visualizan con facilidad y no afectan a otros libros más que a esos. Ese fenómeno se puede ver en El País y los libros de Alfaguara o en El Mundo y las editoriales de su ámbito. No es necesariamente obligatorio que las críticas se hagan con desgana, pues siempre existe la posibilidad de enviarle al crítico las pruebas de autor para que inicie la lectura con el tiempo necesario para la lectura del libro y esté preparado el comentario en el momento de su lanzamiento al mercado. De una u otra forma es muy fácil detectar las irregularidades de calidad, sobre todo cuando hay directores de suplementos o de revistas que se dedican a supervisar los artículos y saben detectar perfectamente cuándo una crítica es real o impostada, cuándo se ha leído el libro el crítico y cuándo no.

Luna Borge realiza un recorrido por autores y críticos, subrayando previamente que un texto sin lectores no sería nada. Destaca así la importante función del lector - que es el primero de los críticos-. Recuerda los casos atípicos de la historia, los autores ignorados en su tiempo. Casos de Góngora y Pessoa, que fueron más leídos con el paso de los años. El primero de ellos fue olvidado y rescatado definitivamente en el primer cuarto del siglo XX. Muchos autores fueron críticos sagaces. Por ejemplo Ezra Pound decía que no había que hacer caso de la crítica de quienes no habían escrito una obra notable. Proust fue primeramente crítico y dejó excelentes artículos sobre Paul Valéry, Miguel de Unamuno o Ruskin. Poe también era un buen crítico, como lo fueron Clarín, Dámaso Alonso, Cernuda, Brines o Valente.

\section{EL CRÍTICO COMO LECTOR PRIVILEGIADO}

Otra de las cuestiones planteadas en el suplemento es la de la obra abierta hasta el infinito. Es decir, una obra puede sugerir tantas interpretaciones como lectores la aborden y los críticos no dejan de ser lectores muy cualificados. A lo largo de los tiempos una obra podrá sugerir nuevas interpretaciones y cada crítico es un eslabón de una cadena que aporta una visión más sobre una determinada obra. Por ejemplo, Góngora es presentado por Dámaso Alonso como autor de una obra innovadora, difícilmente superable y casi definitiva. ¿Acaso no lo era unos siglos antes? La mirada, pues, sobre la obra puede 
cambiar a lo largo de los siglos. La capacidad de sugerencia de una obra de arte puede ser imperecedera.

No obstante, los argumentos que ha de barajar un crítico en su trabajo han de estar basados precisamente en la literatura, en su conocimiento y dominio de ese campo y nunca en su gusto. No basta, pues, con decir me ha gustado el texto, sino que hay que argumentarlo de manera convincente. El crítico debe ser un lector privilegiado que ha de partir de la lectura como experiencia particular y con esta base llegar a conclusiones generales para que al lector le llegue generalizado lo particular e intransferible. El valor de una obra literaria vendría dado por su mayor o menor capacidad generalizadora a lo largo de los tiempos. De ahí que las obras denominadas clásicas son depósitos inagotables de valores. Hay obras que se diluyen y se olvidan y a veces el estudioso las vuelve a sacar a la luz. Por eso es tan importante el papel del crítico o del estudioso, del erudito y necesita conocimiento de la historia literaria, de la filología, pero sobre todo interés por la literatura, amor a los libros. Con estas cualidades, el crítico se convierte en el mediador entre los escritores y los lectores, es el puente de unión. Harían falta críticos que se dedicaran a valorar obras literarias, independientemente del sello editorial donde se publiquen las obras.

La publicación de un libro titulado De brumas y de veras. La crítica literaria en los periódicos, de Víctor Moreno ${ }^{8}$, provoca una larga entrevista a cargo del autor de este artículo poco después de su publicación, pues se trata de un libro provocador y ácido sobre la situación de la crítica literaria en los medios de comunicación. Lógicamente los comentarios sobre este libro no aparecieron en los periódicos de tirada nacional debido a las alusiones que se les hacía a críticos como Rafael Conte, Miguel García Posada, Luis Antonio de Villena y otros, que escribían en los medios de ese ámbito. No obstante, la edición se agotó rápidamente. El autor del libro describe la crítica literaria del momento y explica algunos de los defectos esenciales de los comentaristas literarios más sobresalientes. Sobre su libro manifestaba Moreno que le ha costado una paciencia ilimitada «al tener que confeccionar cientos de fichas y de consultar y releer textos sobre crítica en general y críticos en particular» ${ }^{9}$. Víctor Moreno ${ }^{10}$ afirmaba que le resultaba irreverente que «como lectores tengamos que soportar a unos críticos que no dejan de tomarnos el pelo con sus pedanterías y necedades».

\footnotetext{
${ }^{8}$ Se trata de un libro clave sobre la crítica literaria. Moreno Bayona (1994).

${ }^{9}$ Declaraciones que pertenecen a una entrevista que Antonio Rodríguez le hace a Víctor Moreno con motivo de la aparición de su libro De brumas y de veras (Rodríguez, 1995a).

${ }^{10}$ Víctor Moreno es autor de una docena de libros, cinco de ellos dedicados a la formación del profesorado (El deseo de leer, 1985; El deseo de escribir, 1994; El juego poético en la escuela, 1989; Leer con los cinco sentidos, 2003). Varios dedicados a la investigación histórica en Navarra (Navarra insólita, 1984; Gora Diario de Navarra, 1985; Caínes navarros, 1993; Crímenes en las calles de Pamplona, 1995. Y dos al ensayo (De brumas y de veras, 1994; y La intertextualidad, 1996).
} 
Conviene detenerse en algunas apreciaciones de Víctor Moreno, que hace hincapié en cómo a los críticos les encanta buscar acuerdos y armonías generales entre su discurso y la práctica concreta de los propios escritores. Dice que se trata de aplicar el propio alegato a la realidad, tratando en plan procustiano de encajarla en los esquemas que uno posee. «Si la realidad no se doblega a ellos, si se muestra machaconamente contraria a las personales coordenadas mentales, es que, la pobrecilla, está equivocada» (Rodríguez, 1995a: 30). Las palabras, entonces, ocupan el lugar de los hechos. Primero se teoriza y después se experimenta. Moreno cita a Swift para decir que «un verdadero crítico tiene una cualidad común con una ramera y con un concejal: que no pierden nunca su título o su condición». En general, - continúa- los críticos y los escritores profesionales son seres escogidos, espiritualmente hablando. «Llevarán una vida interior muy tremenda, y se les hará la boca gaseosa citando a Séneca, a Montaigne y al lucero del alba solitaria, pero, en la práctica, aspiran a estar todo el santo año dando la vara publicitario-moral en el púlpito de un periódico» (Rodríguez, 1995a: 30). Subraya que hay muchos críticos, pero duda que se haga verdadera crítica.

Víctor Moreno sostiene en la entrevista que ha centrado su estudio en los periódicos nacionales por una cuestión práctica, ya que llegar a los periódicos de provincia le suponía mucha dificultad. En relación con éstos cita unas palabras de Jorge Herralde, el editor de Anagrama, que, al parecer, afirmaba que la mejor crítica de este país se hacía, precisamente en «esos papeles de provincia».

A mediados de los años 90 el tema de la crítica seguía tan susceptible que continuaban los debates. Precisamente en abril de 1995 Cuadernos del Sur publicó un número titulado «Debate sobre la crítica» ${ }^{11}$ en el que con motivo del inminente fallo del Premio de la Crítica de ese año se hacía una encuesta donde veinte estudiosos (críticos, poetas, escritores, profesores y editores) analizaban la importancia de los galardones nacionales y el sentido de la crítica en ese momento. Algunos de los encuestados manifestaron que dichos galardones eran «demasiado elitistas porque sólo tienen acceso a ellos determinadas personas o círculos literarios» (Rodríguez, 1995b: 28). Casi todos estaban de acuerdo en que es esencial la editorial donde esté publicado el libro para tener alguna vía de acceso al galardón. Es decir, ponían de relieve que se valoraba la uniformidad, la semejanza, frente a lo distinto como rango de diferencia. Creen que el jurado debería ir en defensa de la calidad sobre cualquier otro tipo de interés. Por ejemplo, Andrés Sorel (secretario general de la Asociación Colegial de Escritores de España), decía que «los premios de la Crítica no escapan a las leyes del mercado que rige la actual literatura

${ }^{11}$ Las declaraciones de diversos críticos y creadores las recoge en varias páginas el autor de este artículo en un reportaje titulado «Los Premios Nacionales de la Crítica». En Cuadernos del Sur. Diario de Córdoba. 393, 6-IV-1995, pp. 28, 31-34 (I, V-VIII). 
y que el crítico silencia lo que no interesa al mercado o a sus intereses personales». Admitía que la dependencia de las grandes editoriales está presente a la hora de declarar los finalistas y de los medios de comunicación en que ejercen. Reconocía, igualmente, la fuerza de la publicidad. Por su parte, Antonio Hernández (presidente de la Asociación Andaluza de Críticos Literarios) manifestaba que los premios Andalucía de la Crítica nacieron para contrarrestar la influencia política en los premios nacionales.

El crítico, poeta y novelista Antonio Enrique decía que los escritores de este país no pueden criticar en privado a los críticos e inhibirse públicamente contra el montaje que suponen. También señalaba que además de la presión de las editoriales, «muchísimos críticos no están exentos de un papanatismo atroz. De hecho, las grandes editoriales no necesitan presionar, pues la persuasión funciona como un músculo reflejo» (Rodríguez, 1995b: 33).

Manuel Jurado (crítico, novelista y poeta) manifestaba que la situación actual obedece a la falta de reflejo de la realidad plural de la actividad creativa literaria que se produce en España. Apuntaba como idea que un amplio sector de la crítica de todo el país fuera consultado en una encuesta y con arreglo a estos resultados se estableciera el método de trabajo. «Tal vez así se remodelaría mejor la actividad y se lograría una mayor objetividad» (Rodríguez, 1995b: 33).

El número 423 de Cuadernos del Sur se dedica a la crítica andaluza ${ }^{12}$. Un grupo de poetas, novelistas, profesores y editores valoran la aportación de los suplementos culturales andaluces en la promoción del libro y coinciden en afirmar que en Andalucía se está haciendo una crítica seria, rigurosa y creativa, aunque también echan de menos un marco de difusión más amplio para desarrollar la crítica.

\section{DEBATES Y DISCUSIONES}

En un artículo publicado por el profesor y poeta Manuel Mantero titulado «A propósito de Valente», critica a Luis Goytisolo por unas declaraciones hechas durante una presentación de un libro del poeta donde dijo que el siglo XX ha dejado tres grandes poetas españoles: Antonio Machado, Jaime Gil de Biedma y José Ángel Valente y que Valente ha sido posiblemente el último gran poeta. Tacha las palabras de Luis Goytisolo de «disparates» y se pregunta: «¿Gil de Biedma y Valente, superiores a Juan Ramón Jiménez, Manuel Machado, Miguel de Unamuno, Federico García Lorca, Luis Cernuda, Vicente Aleixandre,

\footnotetext{
${ }^{12}$ El Premio Andalucía de la Crítica acababa de instituirse con el objetivo de contrarrestar los Premios Nacionales de la Crítica, por lo que se recoge en un suplemento el sentir de los críticos y los creadores sobre el nuevo proyecto. Se trata de un reportaje a modo de encuesta que firma Antonio Rodríguez (1995c).
} 
Pedro Salinas, Jorge Guillén, Rafael Alberti, Miguel Hernández o Luis Rosales?». Explica que no era un poeta musical como se decía de él y que fue un poeta social como el resto de los miembros de su generación. Respecto a su actitud sostiene Mantero que fue «un gran soberbio estornudándole su desprecio a todos. Atacaba al sistema pero recibía del sistema su parte honorífica y lucrativa: el Premio Nacional de Poesía, Premio Príncipe de Asturias, Premio Reina Sofía... Y poeta mimado por profesores» (Mantero, 2001). El ataque es rotundo. Dice Mantero textualmente que «sus poemas se basan en encabalgamientos neutros sin voluntad de estilo, su vocabulario es pobretón y reiterativo, y da por hondura lo que es frecuentemente simple emborronamiento. Le falta a su poesía magia, sorpresa, revelación. Sus versos no son memorables, no se quedan en la memoria porque no hay fascinación rítmica» (Mantero, 2001).

Pedro J. de la Peña publica un artículo titulado «Una revisión de la generación del 50», donde hace un acercamiento crítico a las inclusiones y exclusiones en las antologías. El artículo cuestiona las recopilaciones habituales de la citada generación realizadas por José Luis García Martín, Juan García Hortelano, Prieto de Paula y García Jambrina. Dice que los nombres siempre repetidos son apenas ocho: Ángel González, Claudio Rodríguez, Caballero Bonald, Carlos Barral, José Agustín Goytisolo, Jaime Gil de Biedma, Francisco Brines y José Ángel Valente. Y se pregunta que por qué nunca se ponen junto a ellos los nombres de Francisca Aguirre, Manuel Alcántara, Julio Mariscal, Pilar Paz Pasamar, Manuel Ríos Ruiz, César Simón, José Corredor Matheos o Antonio Porpetta, por poner solo algunos de los muchos poetas olvidados. Recuerda cómo en la Antología Parcial de Jaime Ferrán, de la editorial Plaza y Janés, se incorporan nombres como el de Lorenzo Gomis, Enrique Badosa, Alfonso Costafreda, Jorge Folch y el propio Jaime Ferrán, que se agregan a la nómina habitual de los poetas catalanes que escriben en castellano. También reclama la visión de Juan de Dios Ruiz Copete sobre el tema o la de Pedro Rodríguez Pacheco. Este último aporta su antología La línea interior (Cajasur, 1999), que contribuye con un amplio marco de nombres del cincuenta, con poetas como María Victoria Atencia, Manuel Mantero, Fernando Quiñones, Aquilino Duque, Rafael Soto Vergés o Rafael Guillén. Escribe que en la realizada por José Luis García Martín, La Segunda Generación Poética de Posguerra, recoge a veinte poetas, donde además de los habituales están también Carlos Murciano, Juan José Cuadros y Julia Uceda. Incluye a Ángel Crespo, José María Valverde, Félix Grande o Carlos Sahagún, que suelen ser considerados de la generación del 60, en función de las fechas de publicación de sus primeros libros. Insiste el crítico en que se perpetra una especie de «genocidio generacional, cercenando obras de originalidad acusada como son las de Fernando Quiñones, Enrique Badosa, Antonio Gamoneda, Lorenzo Gomis, Francisca Aguirre o Manuel Mantero» (Peña, 2002: 6).

Finalmente, el resultado lo representan dos tendencias basadas en los criterios de la poesía como comunicación —donde estarían Ángel González, 
Francisco Brines, Goytisolo y Gil de Biedma - con tendencia a situarse en un cierto realismo descriptivo de la situación circundante, frente a otros poetas más cercanos a la poesía como conocimiento - Valente, Bonald, Costafreda y Carlos Barral- cuyas obras tienden a una búsqueda interiorizada de las razones del espíritu propio. Con esas dos líneas se simplifica el panorama a nivel didáctico, pero queda inexacto cuando se plantea una búsqueda de la realidad intelectual y estética del grupo. Y esto lo único que hace es tergiversar la realidad en la poesía de mediados del siglo XX.

Otra línea maestra de la crítica parte de la base de libros que tratan de aportar visiones nuevas, como es el caso de Antonio Enrique, tras publicar en 2003 Canon heterodoxo. Vicente Luis Mora escribió las páginas centrales del suplemento. Iniciaba su crítica quejándose de que le parecía insólito que un libro tan ambicioso hubiese sido despachado en algunos medios de comunicación con dos frases. Decía que «esto haya pasado con este ensayo dice mucho de la crítica de este país, y del nulo crédito que tiene allende nuestras fronteras» (Mora, 2003). Decía que en España la crítica se ha convertido en un ajuste de cuentas y que no era de recibo saludar con tanto desprecio la aparición de dicho libro. Dice Mora que es a partir del siglo XX donde Enrique comienza a reescribir una historia diferente (sobre todo de la novela), donde comparecen nombres poco conocidos para los lectores actuales como Vintila Horia, Albalá o Tomás Cabot. Concluye que se puede o no estar de acuerdo con Enrique, pero «en estos tiempos de pensamiento único (el del mercado), una segunda voz (y más si está tan documentada como la de Enrique) merece, al menos, el mayor y más agradecido de los respetos» (Mora, 2003).

También Pedro de la Peña recibe con regocijo la aparición del libro de Antonio Enrique, que en los medios de comunicación nacionales es «acogido con silencio», y en Cuadernos del Sur se le dedican otras páginas centrales casi seguidas a las anteriores. Escribe De la Peña que lo importante ahora es señalar las líneas de fuga que se han venido produciendo en los últimos veinte años con respecto a la poesía oficial eternamente refrendada por el seguidismo de los Premios Nacionales de la Crítica. Y en esas líneas cabe señalar que la heterodoxia actual es anterior y mucho más amplia que la llamada Poesía de la Diferencia $^{13}$, que constituiría tan solo uno de los núcleos articulados de la contesta-

${ }^{13}$ El movimiento de la diferencia, que nació y se desarrolló en torno a Cuadernos del Sur, no se aborda específicamente en este artículo, sino en otro del mismo autor sobre la poesía de la diferencia que se publicará en los próximos meses. No obstante, debe quedar constancia que en Cuadernos del Sur se desarrollaron intensos debates y polémicas sobre el tema, entre las denominadas «poesía de la experiencia» y «poesía de la diferencia». Destaca, entre otros, un artículo de Pedro J. de la Peña, titulado «De la igualdad a la diferencia» (1995), y otro de Antonio Rodríguez Jiménez, titulado «Diferencia versus experiencia» (1996). Estos y otros artículos generaron una áspera controversia y contribuyeron a definir parte de la intrahistoria de la poesía reciente. Se trata, además, de un debate crítico documentado en varios ensayos recientes como los de Araceli Iravedra (2007), Luis Bagué (2006), Diana Cullell (2011), además de textos diversos de Juan José Lanz, entre otros críticos y estudiosos de la poesía contemporánea. 
ción a la tendencia hegemónica. De hecho, en su Canon heterodoxo, Antonio Enrique remonta hasta los años sesenta la escisión entre los poetas oficiales más conocidos de la generación del 50 y el grupo del 60, que ha quedado «emparedado» — como diría Enrique- en la tierra de nadie entre los poetas del 50 y los novísimos. Un «hiato» de la crítica que no significa ningún olvido, sino una desmemoria interesada y a beneficio del empedrado camino de la oficialidad. En el Canon se resaltan nombres como Miguel Fernández, Ángel García López, Manuel Ríos Ruiz, Diego Jesús Jiménez, Antonio Gamoneda, Félix Grande, Soto Vergés, Tundidor, Benito de Lucas, Porpetta, Carlos de la Rica, Rafael Guillén, Francisco Toledano, Arcadio López Casanova, Julio Mariscal, Manuel Mantero, Francisca Aguirre y César Simón, entre otros. Explica De la Peña que si «llegáramos a dar por perdida la batalla de la verdad a beneficio de la exclusión, seríamos colaboradores culpables de una injusticia literaria sin precedentes, en una era en la que, si algo es fácil de obtener, es información» (Peña, 2003: 6). Ataca a críticos y antólogos que ignoran voluntariamente todo lo que no les conviene saber. Añade el comentarista que lo que se producen son «egoísmos insufribles, intereses mercantiles y mezquindades dolosas que solo elogian a los muertos» (Peña, 2003: 7). Vuelve otra vez a los años 80 para decir que la poesía ya no reside en los textos sino en la marca de la escudería del autor, que es bueno o malo según los intereses del suplemento cultural en que aparezca. «Cuanto más libertad para escribir, más libertad para mentir», parece ser el lema de cada una de las empresas mediáticas existentes. De ahí que la poesía hegemónica no se convierta ya solo en preeminencia sino en voluntaria colaboradora de la exclusión de todos aquellos que no contribuyan en la nómina de servicios prestados.

Señala De la Peña cómo Antonio Enrique pone sobre la mesa las alternativas de calidad a la poesía neorrealista, que se acomodó e instaló al servicio de una estética realista, totalmente superada y muerta desde su nacimiento. Ensalza otras estéticas de la época, como la poesía pura defendida por Valente y suscrita por Sánchez Robayna, o incluso el realismo de Wolfe o la experiencia de la vida urbana, todo - dice- menos la pobreza verbal y mental de los oficialistas. De la Peña subraya que la heterodoxia tiene menos presente pero más futuro. Sale menos o nada en los boletines oficiales de la cultura, pero despierta el interés de los amantes de la poesía. Gasta mucha menos tinta de periódico, pero es mucho más apreciada por la crítica rigurosa. No canta lo obvio, pero sí lo venidero. Añade De la Peña que si «la crítica periódica tuviera algún valor — que rara vez lo tiene, por ser ignorantes en la materia la mayoría de los cultivadores - hace ya tiempo que hubiese dejado de prestar atención a ese lastre que no hace otra cosa que impedir la legítima evolución de nuestras letras. Pero los creadores más significativos, los cultivadores de las distintas heterodoxias existentes, ésos hace ya largo tiempo que se desmarcaron de la clonación literaria y han echado a andar por su propio camino, como demuestra la bibliografía que hemos ido aportando» (Peña, 2003: 7). 
Al final todo se convierte en un ejercicio de libertad que no todos pueden ejercer. La libertad de escribir lo que uno quiere, sin pautas ni filiaciones encadenantes es el don más hermoso. Y es eso lo que algunos críticos no han comprendido de los heterodoxos cuando afirman que éstos desearían recibir los honores y premios de los poetas epigonales. Quizás la satisfacción de ser el eco de la voz de otro les pueda ser rentable a algunos, pero desde luego, a los creadores de verdad no les satisface mucho, añade De la Peña.

Estas son algunas de las líneas maestras de las críticas más destacables desarrolladas a lo largo de los años en las diferentes etapas de Cuadernos del Sur. Debates, coloquios, reflexiones —además de los propios comentarios sobre las obras - marcan las características y referentes de una crítica que se produce en un periódico y que adquiere el brillo de la crítica más estricta de una revista especializada, sencillamente porque el suplemento, a nivel crítico, aspiró al ejercicio de una crítica clara, exigente, veraz, capaz de contagiar a los lectores el amor por los libros.

\section{FUENTES PRIMARIAS}

Cerezo Aranda, José Antonio (1987). «El amor del último Miller», Cuadernos del Sur. Diario Córdoba. 6, 15 enero, p. 19.

Chicharro Chamorro, Antonio (1989). «Sobre el conocimiento crítico literario», Cuadernos del Sur. Diario Córdoba. 100, 9 de febrero, p. 14.

Conte, Rafael (1990). «La novela española, bajo sospecha», Cuadernos del Sur. Diario Córdoba. 155, 5 de abril, p. 25.

García Martín, José Luis (1987). «Palabras para un tiempo de silencio, La poesía y la novela de la generación del 50», Revista Olvidos de Granada. 13, ¿PP?

García Martín, José Luis (1988a). «Nuevos poemas viejos de Gimferrer», Cuadernos del Sur. Diario Córdoba. 65, 28 de abril, p. 3.

García Martín, José Luis (1988b). «Un mágico alfabeto», Cuadernos del Sur. Diario Córdoba. 66, 5 de mayo, p. 7.

García Martín, José Luis (1989). «Una habitación propia», Cuadernos del Sur. Diario Córdoba. 100, 9 de febrero, p. 15.

García Posada, Miguel (1990). «Entre poetas anda el juego», Cuadernos del Sur. Diario Córdoba. 155, 5 de abril, p. 24.

Garrido Moraga, Antonio (1989). «Función de la crítica literaria», Cuadernos del Sur. Diario Córdoba. 100, 9 febrero, p. 15.

Lanz, Juan José (1991). «El lector como crítico y el crítico como lector», Cuadernos del Sur. Diario Córdoba. 221, 26 de septiembre, p. 27.

López Gorgé, Jacinto (1987). «Profesionalidad de la crítica», Cuadernos del Sur. Diario Córdoba. 34, 10 de septiembre, p. 22.

López Gutiérrez, Francisco (1988). «La neonarrativa urbana», Cuadernos del Sur. Diario Córdoba. 84, 13 de octubre, p. 3.

Luna Borge, José (1987). «Las excelentes maneras de un joven poeta», Cuadernos del Sur. Diario Córdoba. 26, 4 de junio, p. 23.

Luna Borge, José (1987). «Javier Salvago: un poeta entre el sentimiento y el humor», Cuadernos del Sur. Diario Córdoba. 30, 9 de julio, p. 19. 
Luna Borge, José (1991). «Crisis crítica», Cuadernos del Sur. Diario Córdoba. 228, 14 de noviembre, pp. 28-29.

Malpartida, Juan (1990). «El ensayo y el poder», Cuadernos del Sur. Diario Córdoba. 155, 5 de abril, p. 26.

Mantero, Manuel (2001). «A propósito de Valente», Cuadernos del Sur. Diario Córdoba. 670, 1 de enero, p. 5.

Martín, José Manuel (1986). «El gran cuaderno, un ejercicio de angustia de Agota Kristof», Cuadernos del Sur. Diario Córdoba. 1, 27 de noviembre, p. 22.

Mora, Vicente Luis (2003). «Un canon alternativo», Cuadernos del Sur. Diario Córdoba. 767,8 de mayo, p. 6.

Peña, Pedro J. de la (1995). «De la igualdad a la diferencia», Cuadernos del Sur. Diario Córdoba. 384, 2 de febrero, pp. 8.

Peña, Pedro J. de la (2002). «Una revisión de la generación del 50», Cuadernos del Sur. Diario Córdoba. 747, 12 de diciembre, pp. 6-7.

Peña, Pedro J. de la (2003). «Elogio de la heterodoxia», Cuadernos del Sur. Diario Córdoba. 773, 19 de junio, pp. 6-7.

Pérez Ponferrada, Gonzalo (1987). «Un polifacético personaje», Cuadernos del Sur. Diario Córdoba. 24, 21 de mayo, p. 21.

Rodríguez Jiménez, Antonio (1995). «Las brumas de Víctor Moreno», Cuadernos del Sur. Diario Córdoba. 390, 16 de marzo, pp. 30-31.

Rodríguez Jiménez, Antonio (1995). «Los Premios nacionales de la Crítica», Cuadernos del Sur. Diario Córdoba. 393, 6 de abril, pp. 28-34.

Rodríguez Jiménez, Antonio (1995). «Atención a las literaturas periféricas», Cuadernos del Sur. Diario Córdoba. 423, 14 de diciembre, pp. 32-33.

Rodríguez Jiménez, Antonio (1996). «Diferencia versus experiencia», Claves de la Razón Práctica. 50, pp. 32-33.

Roso, Pedro (1986). «Una antología de Carlos Clementson», Cuadernos del Sur. Diario Córdoba. 1, 27 de noviembre, p. 19.

Roso, Pedro (1987a). «Para qué la lírica hoy?», Cuadernos del Sur. Diario Córdoba. 8, 29 de enero, p. 19.

Roso, Pedro (1987b). «Tres poéticas y un manifiesto», Cuadernos del Sur. Diario Córdoba. 10, 12 de febrero, p. 19.

Roso, Pedro (1987c). «Vázquez Montalbán, entre Carvalho y Pigmalión», Cuadernos del Sur. Diario Córdoba. 24, 21 de mayo, p. 19.

Roso, Pedro (1989). «Límites y función de la crítica literaria», Cuadernos del Sur. Diario Córdoba. 100, 9 de febrero, p. 10.

Rubio, Fanny (1987). «La imagen poética de Manuel Andújar», Cuadernos del Sur. Diario Córdoba. 29, 2 de julio, p. 21.

Ruiz Pérez, Pedro (1989). «El discurso de la crítica o la crítica como discurso», Cuadernos del Sur. Diario Córdoba. 100, 9 de febrero, p. 16.

Sanz Villanueva, Santos (1987). «Andújar, hombre de letras», Cuadernos del Sur. Diario Córdoba. 29, 2 de julio, p. 20.

Sueiro, Susana (1988). «La escritura de Carmen Martín Gaite», Cuadernos del Sur. Diario Córdoba. 84, 13 de octubre, p. 7.

\section{BIBLIOGRAFÍA CITADA}

Bagué, Luis (2006). Poesía en pie de paz. Modos del compromiso hacia el tercer milenio. Valencia: Pre-Textos. 
Cullell, Diana (2011). La poesía de la experiencia española. Madrid: Devenir.

Debicki, Andrew P. (1987). Poesía del conocimiento. La generación española de 1956-1971. Gijón: Júcar.

Domin, Hilde (1986). ¿Para qué la lírica hoy? Madrid: Alfa.

García Martín, José Luis (1986). La segunda generación poética de postguerra. Badajoz: Diputación.

Iravedra, Araceli (2007). Poesía de la experiencia. Madrid: Visor.

Moreno Bayona, Víctor (1994). De brumas y de veras. La crítica literaria en los periódicos. Pamplona: Pamiela.

Fecha de recepción: 9 de octubre de 2013.

Fecha de aceptación: 20 de febrero de 2014. 